\title{
Comparative Adsorption Study of the Removal of Cadmium (II) By PVAC-SP and ACSP
}

\author{
Kanchan Deep Chaudhary, Vimla Chaudhary \\ Dept. of chemistry, Jainarain Vyas University, Jodhpur
}

\begin{abstract}
The aim of investigating the removal of Cd(II) from wastewater by Poly vinyl alcohol coated activated carbon derived from stem of Salvadora persica (PVAC-SP) was found to have a good non conventional adsorbent. Most of the studies indicate that the adsorption of Cd (II) increased with the increased $p H$ value. In the present study $p H 5$ and contact time of 150 min. was found to be optimum for ACSP and $p H 5$ and contact time 120min. for PVAC-SP. The effect of doses shows that activated charcoal derived from Salvadora persica of 2.5 gram dose could remove the $81.7 \mathrm{Cd}$ (II) and poly vinyl alcohol coated carbon of Salvadora persica of 2 gram remove the $91.2 \% \mathrm{Cd}(\mathrm{II})$ from water and the adsorption conformed to the Freundlich and Langmuir adsorption isotherm. The values of constant for the isotherms were found. Comprehensive characterization of parameters indicates PVAC-SP to be a good adsorption material for treatment of Cd(II) from wastewater.
\end{abstract}

Keywords: Heavy metal-cadmium, adsorption isotherm, Salvadora persica, activated charcoal, Poly vinyl alcohol. Abbreviation: ACSP-Activated Carbon of Salvadora persica PVAC-SP Poly vinyl alcohol coated carbon of Salvadora persica.

\section{Introduction}

The tremendous increase in the use of heavy metals ${ }^{(1)}$ over the past few decades resulted in an increased flux of metallic substances in the aquatic environment. The metals are of special concern because of their persistency. Industrial waste constitutes the major source of various kinds of metal pollution in natural water. The important toxic metals are $\mathrm{Cd}, \mathrm{As}, \mathrm{Zn}, \mathrm{Pb}$ and $\mathrm{Ni}$. These heavy toxic metals entered into the water bodies through waste water from metal plating industries and industries of $\mathrm{Cd}$ - Ni batteries, phosphate fertilizer, mining, pigments, and stabilizers alloys . The metal ions i.e. $\mathrm{Cd}^{+2}, \mathrm{Zn}^{+2} \mathrm{Ni}^{+2}$ and $\mathrm{Pb}^{+2}$ are important heavy metals in the water system since they are micronutrients in plants and animals including man. The effects of cadmium poisoning in humans are serious, among them are high blood pressure, kidney damage and destruction of testicular tissues and red blood vessels (RBCs). A numbers of technologies have been developed over the years to remove toxic metals from water. The most important technologies includephysico-chemical treatment $^{(8,11 \mathrm{~s})}$ such as chemical precipitations, electro flotation ${ }^{(6,9)}$, ion exchange, reverse osmosis, and adsorption ${ }^{(9)}$ on activated carbon. These methods are not cost effective. The high cost of activated charcoal has prompted a search for cheaper substitutes. Low cost adsorbents ${ }^{(3,7)}$ includes agricultural wastes like natural compost, Irish peanut, peanut shell ${ }^{(5)}$, coconut shell, bone and biomass such as Aspergilus tereus and mucus remanianus, polymerized onion skin with formaldehyde and EDTA, fly ash ${ }^{(4)}$, natural materials such as hair and cattails (Thypha Plant) waste wool, peanut skin, modified barks, barely straw low rank coal, soils, human hair , peat moss , fertilizer waste slurry, waste tyre rubber and tea leaves .

In the present investigation attempts have been made to assess the efficiency of low cost adsorbent ${ }^{(7)}$ material prepared from S. persica stem for removal of $\mathrm{Cd}(\mathrm{II})^{(2)}$ from wastewater. The influence of various factors, such as adsorbent loadings, initial $\mathrm{pH}$, time and initial metal ion concentration on the adsorption capacity were studied.

The Langmuir and Freundlich models were used to analyze the adsorption equilibrium.

\section{Material and Methods:}

Preparation of polyvinyl alcohol coated carbon of Salvadora persica (PVAC-SP):

The naturally dried bark of the plant Salvadora persica were obtained locally. It cut into small pieces and air dried for $48 \mathrm{~h}$. Bark were treated with $2 \% \mathrm{v} / \mathrm{v}$ sulphuric acid in 1:1 ratio, kept in oven at $150 \mathrm{C}$ for 24 hours and then filtered and washed with distilled water repeatedly to remove sulphuric acid(washing tested with two drops of barium chloride $(\mathrm{BaCl} 2)$ solution) and finally dried in oven at $300^{\circ} \mathrm{c}$ and powdered using mortar and pestle.

Chemical activation of carbon using sulphuric acid produces a high surface area and high degree of microporosity. 
Polyvinyl alcohol is good hydrophilic polymer and has water-adsorbing capacity. The powdered ACSP was treated with an emulsion of readily available synthetic polymer-PVA. Nine parts by weight of activated carbon obtained from the stem of Salvadora persica were mixed with one part by weight of PVA to form a semisolid mass. The agglomerated product was dried and ground into fine powder. The adsorbent was sieved to 40-60 mesh size and dried at $110^{\circ} \mathrm{C}$ for 2 hours.

This powder was then used as an adsorbing material.

\section{Adsorbate:}

A stock solution of cadmium $(2 \mathrm{mg} / \mathrm{ml})$ was prepared by dissolving $\mathrm{Cd}(\mathrm{NO} 3)_{2} .4 \mathrm{H} 2 \mathrm{O}$ in $0.1 \mathrm{M} \mathrm{HNO}_{3}$. The solution was standardized complex metrically with EDTA (disodium salt) using Xylenol orange indicator.

\section{Batch adsorption studies:}

The experiments were carried out in the batch mode for the measurements of adsorption capacities . The effect of $\mathrm{pH}(3,4,5,6,7$ and 8$)$, contact time (30-150 min), adsorbent dose (.5-3.5 g/l) and initial metal ion concentration $(60-180 \mathrm{mg} / \mathrm{l})$ at room temperature using stopper bottles. The initial $\mathrm{pH}$ of solution was adjusted by using $0.05 \mathrm{~N} \mathrm{HCl}$ or $0.1 \mathrm{~N} \mathrm{NaOH}$ without changing the volume of the sample. After agitating the sample for the required contact time, the contents were centrifuged and filtered through Whatman No.41 filter paper and unreacted cadmium in the filtrate was analyzed by atomic absorption spectrophotometer .

The removal efficiency $(\mathrm{E})$ of adsorbent was defined as:

$\mathrm{E}(\%)=[(\mathrm{Co}-\mathrm{Ce}) / \mathrm{Co}] \times 100$

Where $\mathrm{Co}$ and $\mathrm{Ce}$ are the initial and equilibrium concentration of metal ion solution $(\mathrm{mg} / \mathrm{L})$, respectively.

\section{Adsorption kinetics Of Cd (II): \\ Freundlich Adsorption Isotherm:}

Freundlich Isotherm is represented by the following equation: $\log q \mathrm{e}=\log \mathrm{Kf}+1 / \mathrm{n} \log \mathrm{Ce}$

Where;

$\mathrm{qe}=$ the amount of adsorbate adsorbed per unit mass of adsorbent (mg adsorbate/g adsorbent)

$\mathrm{K}_{\mathrm{f}}=$ adsorption capacity

$\mathrm{n}=$ adsorption intensity are the empirical constants.

$\mathrm{Ce}=$ equilibrium concentration of adsorbate $(\mathrm{mg} / \mathrm{L})$

The Freundlich expression is an empirical equation based on a heterogeneous surface.

A plot between $\log \mathrm{Ce}$ and $\log$ qe gives a straight line and It is also observed that the Freundlich isotherm model is well fitted for the metal ions.(fig: 5a and 5b for ACSPand PVAC-SP respectively).

\section{Langmuir Adsorption Isotherm:}

Langmuir Isotherm is represented by the following equation: $\mathrm{Ce} / \mathrm{q}_{\mathrm{e}}=1 / \mathrm{q}_{\max } \mathrm{b}+\mathrm{Ce} / \mathrm{q}$ Where,

$\mathrm{q}_{\max }=$ maximum metal uptake corresponding to the saturation capacity of the adsorbent

$\mathrm{b}=$ energy of adsorption.

$\mathrm{q}_{\mathrm{e}}=$ the amount of metal adsorbed on the activated carbon

$\mathrm{Ce}=$ equilibrium metal concentration in the solution

The constants $\mathrm{q}_{\max }$ and $\mathrm{b}$ are the characteristics of the Langmuir isotherm and can be determined from (2). Therefore a plot of Ce/qe versus Ce gives a straight line of slope $\left(1 / \mathrm{q}_{\max }\right)$ and intercept $\left(1 / \mathrm{bq}_{\max }\right)$. The data fit the Langmuir isotherms model well for Cd(II) ions .The values of Langmuir parameters for the removal of Cd(II) metal ions by ACSP are presented in Table 1a and that of PVAC-SP in table 2a. The linearity of the two plots (Fig. 5a and 5b) for ACSP and PVAC-SP respectively indicates application of the Langmuir equation, supporting monolayer formation on the surface of the adsorption. The values of $b$ and $\mathrm{q}_{\max }$ indicate that the adsorption of the metal ions are concentration and $\mathrm{pH}$ dependent. The expression of separation factor (RL) in the dimensionless form of the Langmuir isotherm is

$$
\mathrm{RL}=1=\left(1+\mathrm{b} \mathrm{C}_{0}\right) \text {, }
$$

where $\mathrm{C}_{0}$ is the initial concentration of metal ion and $\mathrm{b}$ is the Langmuir constant. The separation factor (RL) can be used to predict affinity between the sorbate and sorbent in the adsorption system. The characteristics of the RL value indicates the nature of biosorption as

unfavourable when $(\mathrm{RL}>1)$

linear when $(\mathrm{RL}=1)$,

favourable when $(0<R L<1)$, and

irreversible when $(R L=0)$. 
It is well observed that, in all selected concentrations $(60-180 \mathrm{mg} / \mathrm{l})$ of metal ions, the separation factor $(\mathrm{RL})$ is less than 1.0 indicating the favourable adsorption conditions.

\section{Effect of contact time:}

\section{Result and Discussion}

In adsorption system, the contact time play a vital role irrespective of the other experimental parameters, affecting the adsorption kinetics. Figure 1 depicts the effect of contact time on percent removal of $\mathrm{Cd}(\mathrm{II})$. In the case of adsorbent used, there was an appreciable increase in percent removal of metal up to 150 minutes for ACMO and 120 minutes for PVAC-MO and thereafter further increase in contact time, the increase in percent removal was very small. Thus the effective contact time is taken as $150 \mathrm{~min}$. for ACSP and $120 \mathrm{~min}$. for PVAC-SP adsorbents and it is independent of initial concentration (shows in figure 1).

\section{Effect of pH:}

The adsorptive capacity of Salvadora persica was dependent on $\mathrm{pH}$ of cadmium solution. At lower $\mathrm{pH}$ values, the large number of $\mathrm{H}+$ ions neutralizes the negatively charged adsorbent surfaces, there by reducing hindrance of the $\mathrm{Cd}(\mathrm{II})$ ions, At the high $\mathrm{pH}$ values, the reduction in adsorption may be due to the abundance of $\mathrm{OH}$ - ions causing increased hindrance to diffusion of $\mathrm{Cd}(\mathrm{II})$ ions.

For both ACSP and PVAC-SP at the $\mathrm{pH}$ 5, the percent removal of Cd(II) ion increase sharply, attaining values that stay almost constant. There after the percent removal decreases with increase in $\mathrm{pH}$ (shows in figure 2)

\section{Effect of adsorbent dose:}

The effect of adsorbent dose on percent removal of Cd(II) is shown in figure 3. Adsorbent dose was varied between $.5-3.5 \mathrm{~g} / 1$ for adsorbents used. The percent removal of $\mathrm{Cd}$ (II) increases at a faster rate initially with increases in adsorbent dose. For ACSP, percent removal was found to be increasing with increase in adsorbent dose upto $2.5 \mathrm{~g} / \mathrm{l}$. Thus, the effective dose of ACPC was considered as $2.5 \mathrm{~g} / \mathrm{l}$. In case of PVAC-SP removal rate was found to be moderate after $2 \mathrm{~g} / \mathrm{l}$.

\section{Effect of initial metal ion concentration:}

Effect of initial Cd (II) ion concentration over the percent removal of $\mathrm{Cd}(\mathrm{II})$ is shown in figure 4 and shows that, as the concentration of $\mathrm{Cd}(\mathrm{II})$ in solution increases, the percent removal of $\mathrm{Cd}(\mathrm{II})$ decreases for both the adsorbents used. These results may be explained on the basis that the increase in the number of ions competing for the available binding sites and also because of the lack of active sites on the adsorbent at higher concentration.

There were more metal ions were left unadsorbed in solution at higher concentration levels.

\section{Results of adsorption isotherms}

Langmuir and Freundlich isotherm for Cd(II) were found to be linear showing the applicability of the isotherms (Figure 5 and 6). The values of Langmuir and Freundlich constants calculated from the graph are summarized in Table 1 for Cd(II) adsorption by ACSP and PVAC-SP. Value of n, was 1.67504 for Cd(II) at effective dose and contact time of the ACSP and Values of $n$, was for Cd(II) at effective dose and contact time of the ACSP and Values of n, was 2.11595 for Cd(II) of the PVAC-SP. Indicates good adsorption potential of the PVAC-SP.

Kinetic study: Based on linear regression $\left(\mathrm{R}^{2}\right)$ values, the kinetics of Cd(II) adsorption onto ACSP and PVACSP can be described well by pseudo second order equation.

\section{Conclusion}

1. The present study demonstrates the utility of adsorbents such ACSP and PVAC-SP. These raw adsorbent are easily, locally and cheaply available and require a small degree of pre-treatment before their utilization.

2. The efficiency of PVAC-SP as an adsorbent is superior to that of ACSP.

3. The maximum percent removal of Cd(II) was found to be $88.6 \%$ and $76.8 \%$ with PVAC-SP and ACSP at $\mathrm{pH}$ 6 for both adsorbent.

4. Both adsorbents used follow Freundlich and Langmuir isotherm models.

5. Extent of removal depends on the $\mathrm{Cd}$ ion concentration and $\mathrm{pH}$

6. Adsorption capacity of PVAC-SP was grater then ACSP.

7. We can use PVAC-SP for removal of other metal ions or dyes from wastewater. 


\section{References}

[1] S.S. Ahluwalia, D. Goyal, Microbial and plant derived biomass for removal of heavy metals from wastewater Bioresour. Technol., 98 (12) (2006), pp. 2243-2257

Abu-Eishah, 2008

S.I. Abu-Eishah

[2] Removal of $\mathrm{Zn}, \mathrm{Cd}$, and $\mathrm{Pb}$ ions from water by Sarooj clay

Appl. Clay Sci., 42 (1-2) (2008), pp. 201-205

Babel and Kurniawan, 2003

S. Babel, T.A. Kurniawan

[3] Low-cost adsorbents for heavy metals uptake from contaminated water: a review

J. Hazard. Mater., B97 (2003), pp. 219-243

i, M. Sharma, S.K. Saini

[4] Removal of cadmium and nickel from wastewater using bagasse fly ash - a sugar industry waste

Water Res., 37 (2003), pp. 4038-4044

Bansode et al., 2003

P.R. Bansode, J.N. Losso, W.E. Marshall, R.M. Rao, R.J. Portier

[5] Adsorption of metal ions by peanut shell-based granular activated carbons

Bioresour. Technol., 89 (2003), pp. 115-119

Jakobsen et al., 2004

M.R. Jakobsen, J.F. Rasmussen, S. Nielsen, L.M. Ottosen

[6] Electrodialytic removal of cadmium from wastewater sludge

J. Hazard. Mater., 106B (2004), pp. 127-13

Kurniawan et al., 2005

T.A. Kurniawan, G.Y.S. Chan, W.H. Lo, S. Babel

[7] Comparisons of low-cost adsorbents for treating wastewaters laden with heavy metals

Sci. Total Environ., 366 (2-3) (2005), pp. 409-426

Kurniawan et al., 2006

T.A. Kurniawan, G.Y.S. Chan, W.H. Lo, S. Babel

[8] Physico-chemical treatment techniques for wastewater laden with heavy metals

Chem. Eng. J., 118 (2006), pp. 83-98

Mavrov et al., 2003

V. Mavrov, T. Erwe, C. Blocher, H. Chmiel

[9] Study of new integrated processes combining adsorption, membrane separation and flotation for heavy metal removal from wastewater

Desalination, 157 (2003), pp. 97-104

[10] Removal of heavy metal ions from wastewaters: A review

2011, Journal of Environmental Management

[11] Physico-chemical treatment techniques for wastewater laden with heavy metals 2006, Chemical Engineering Journal

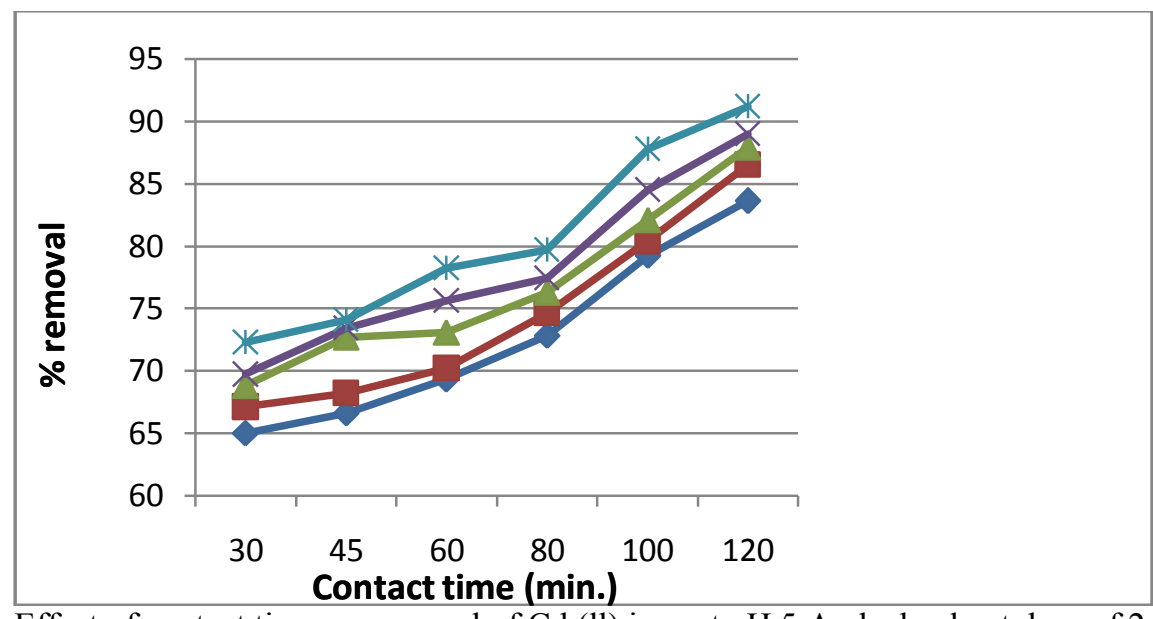

Fig 1 (a) : Effect of contact time on removal of Cd (11) ions at pH 5 And adsorbent dose of $2.5 \mathrm{~g}$ (ACSP) 


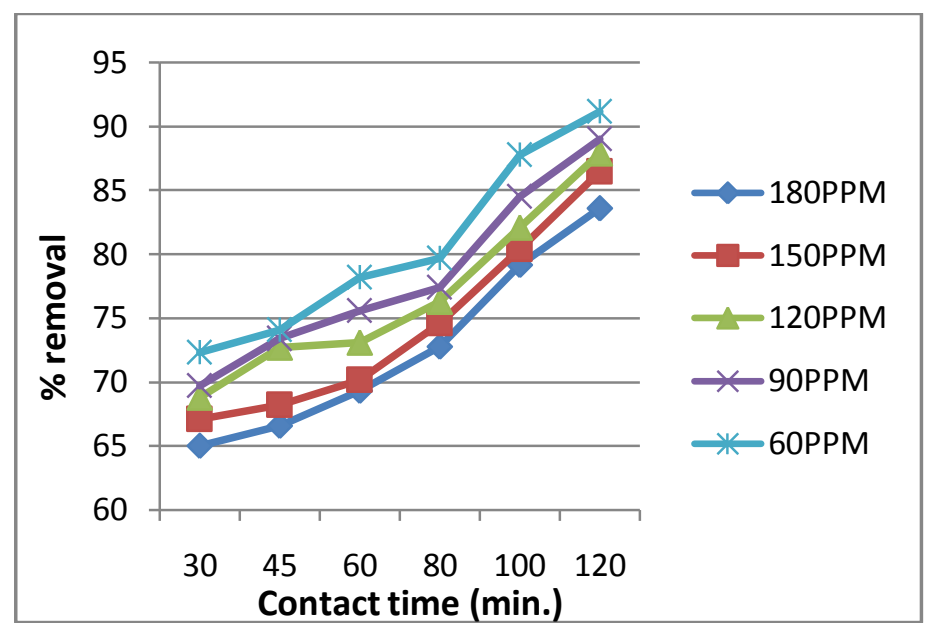

Fig 1 (b) : Effect of contact time on removal of Cd (1l) ions at $\mathrm{pH} 5$ And adsorbent dose of $2 \mathrm{~g}$ (PVAC-SP)

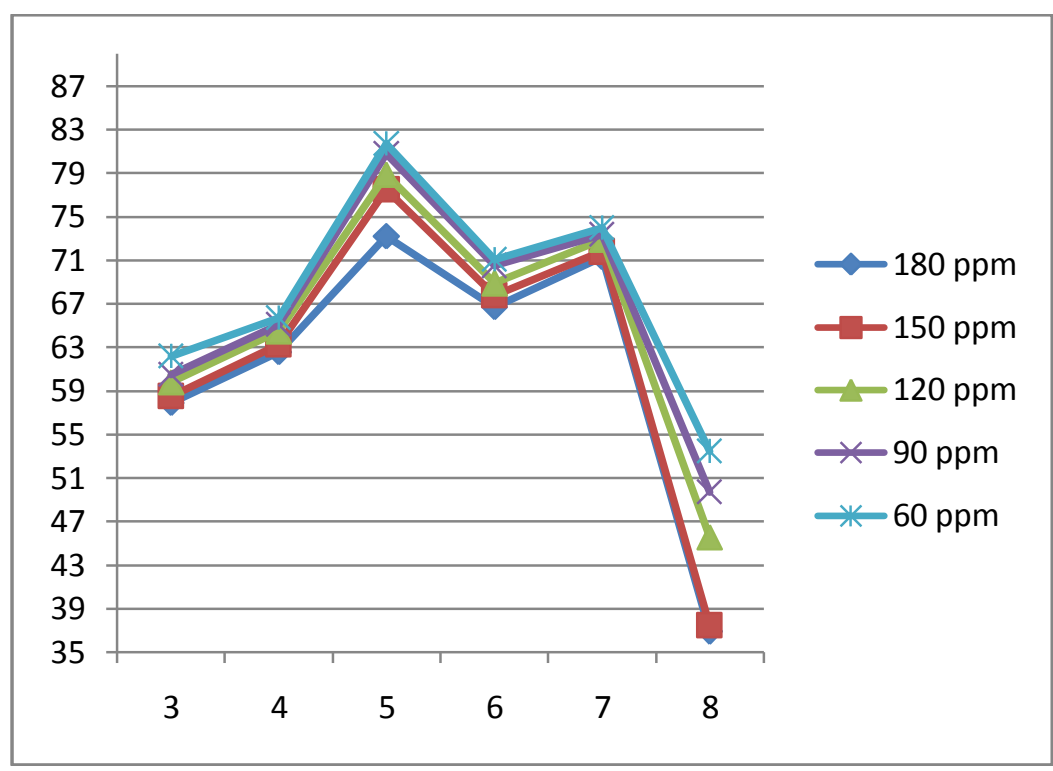

Fig 2 (a): Effect of $\mathrm{pH}$ on removal of Cd (11) ions at time $150 \mathrm{~min}$ and adsorbent dose $2.5 \mathrm{~g}$ (ACSP)

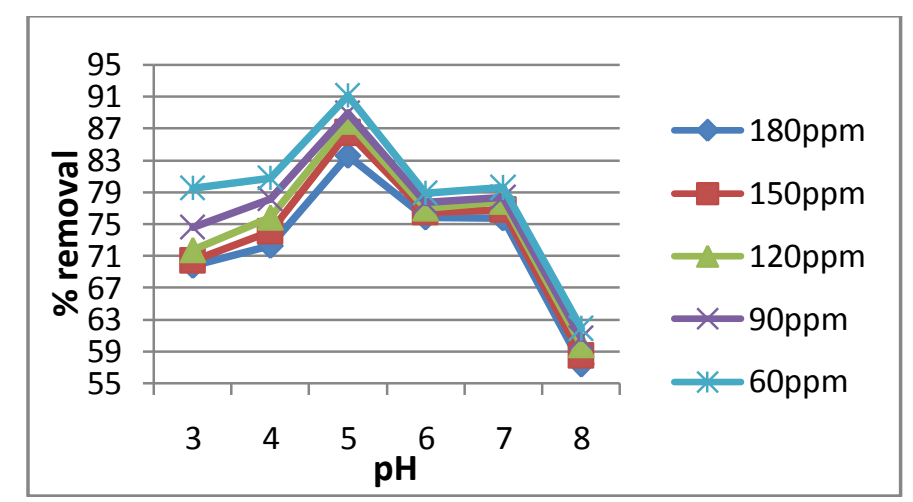

Fig 2 (b) : Effect of $\mathrm{pH}$ on removal of Cd (1l) ions at time $120 \mathrm{~min}$ and adsorbent dose 2g(PVAC-SP) 


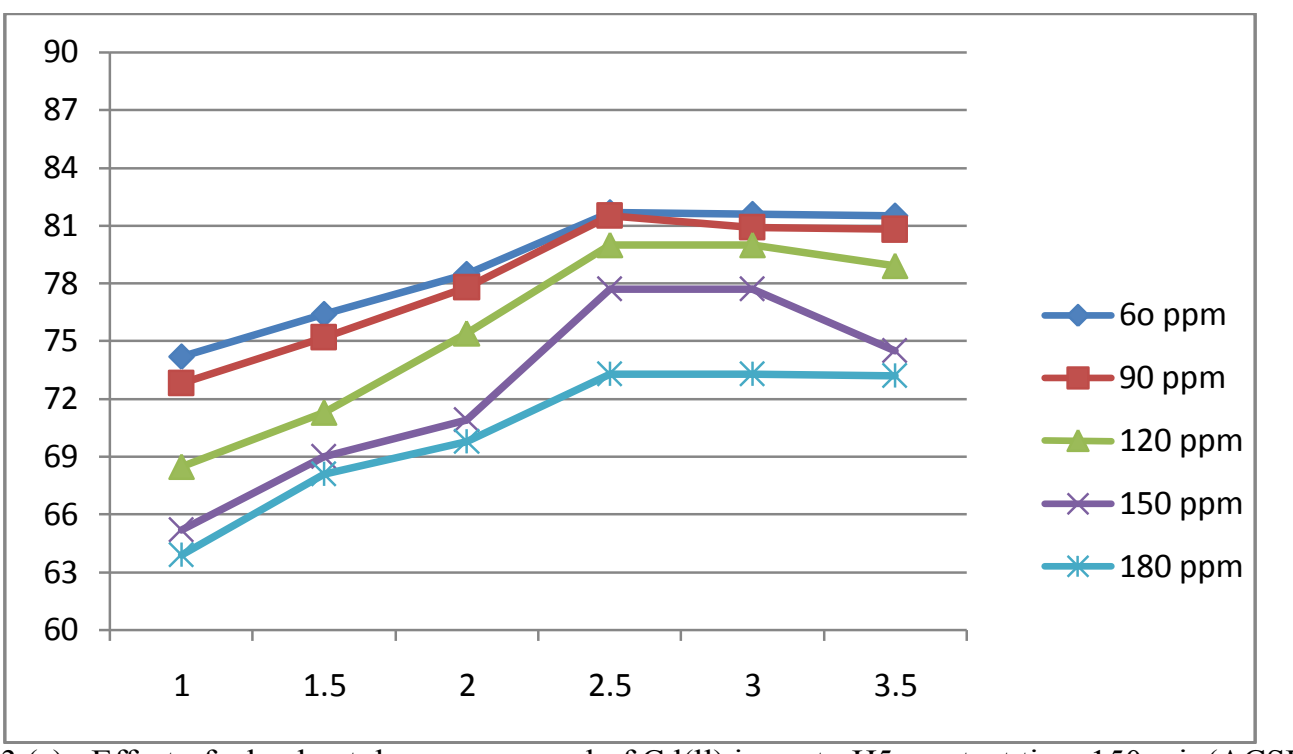

Fig 3 (a) : Effect of adsorbent dose on removal of Cd(11) ions at pH5, contact time $150 \mathrm{~min}$ (ACSP)

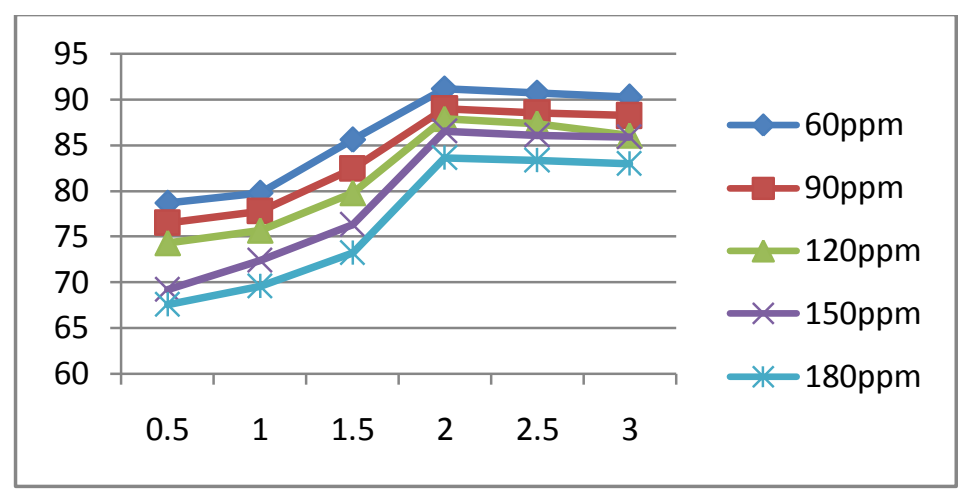

Fig 3 (b) : Effect of adsorbent dose on removal of Cd(11) ions at pH5, contact time $120 \mathrm{~min}$ (PVAC-SP)

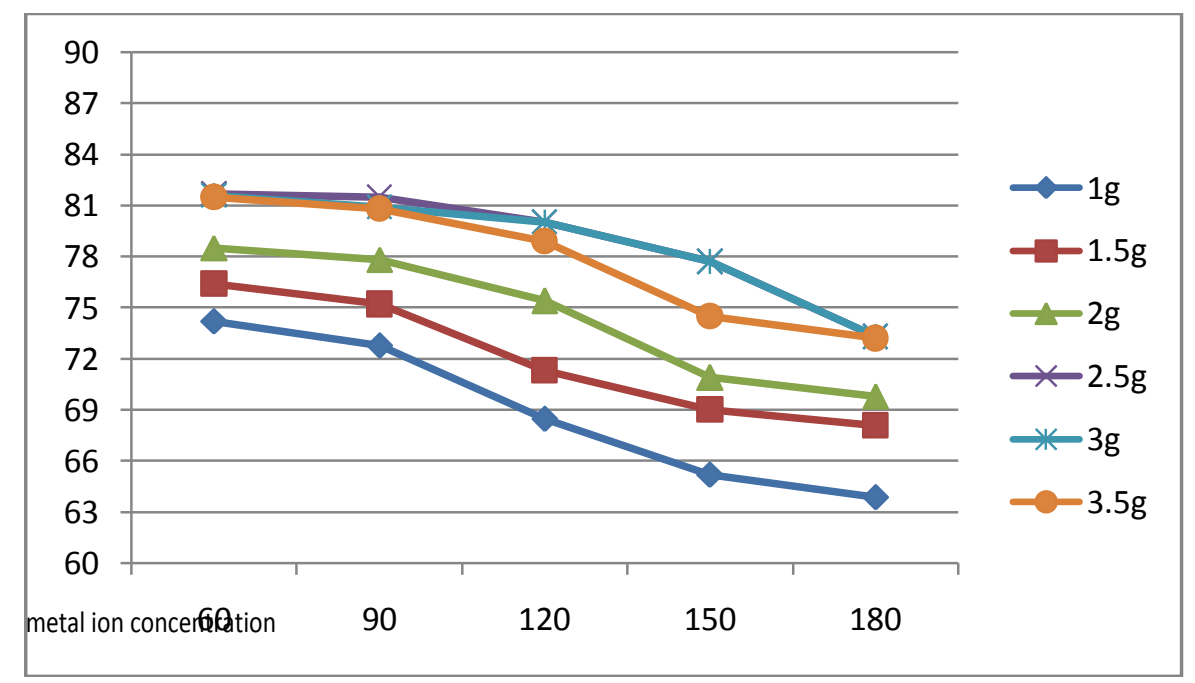

Fig 4 (a): Effect of metal ion concentration on removal of Cd (11) ions at pH 5 (ACSP) 


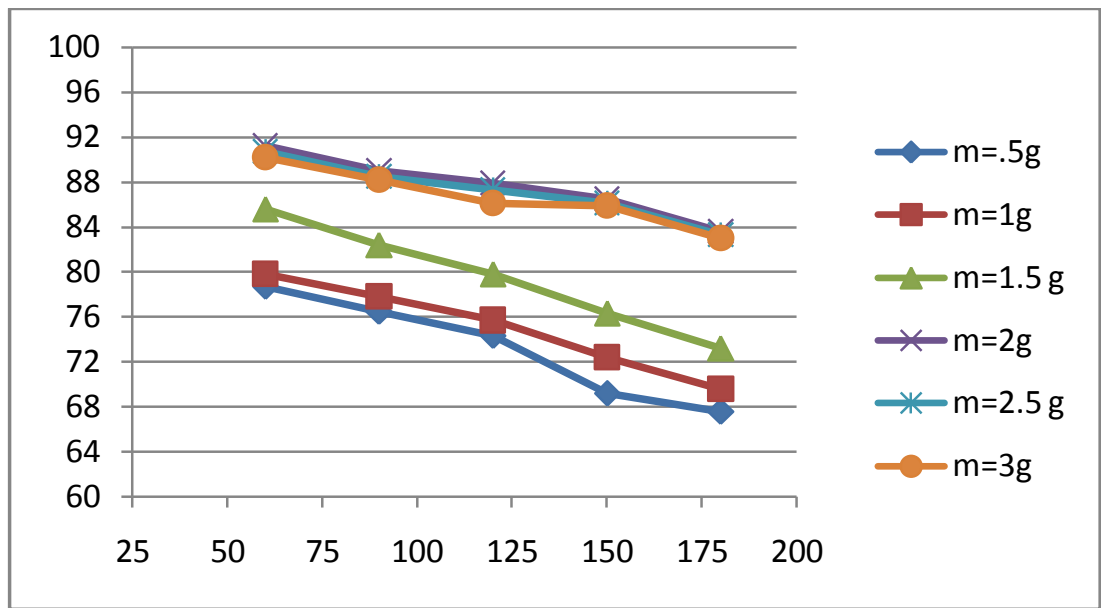

Fig 4 (b): effect of metal ion concentration on removal of Cd (11) ions at pH 5 (PVAC-SP)

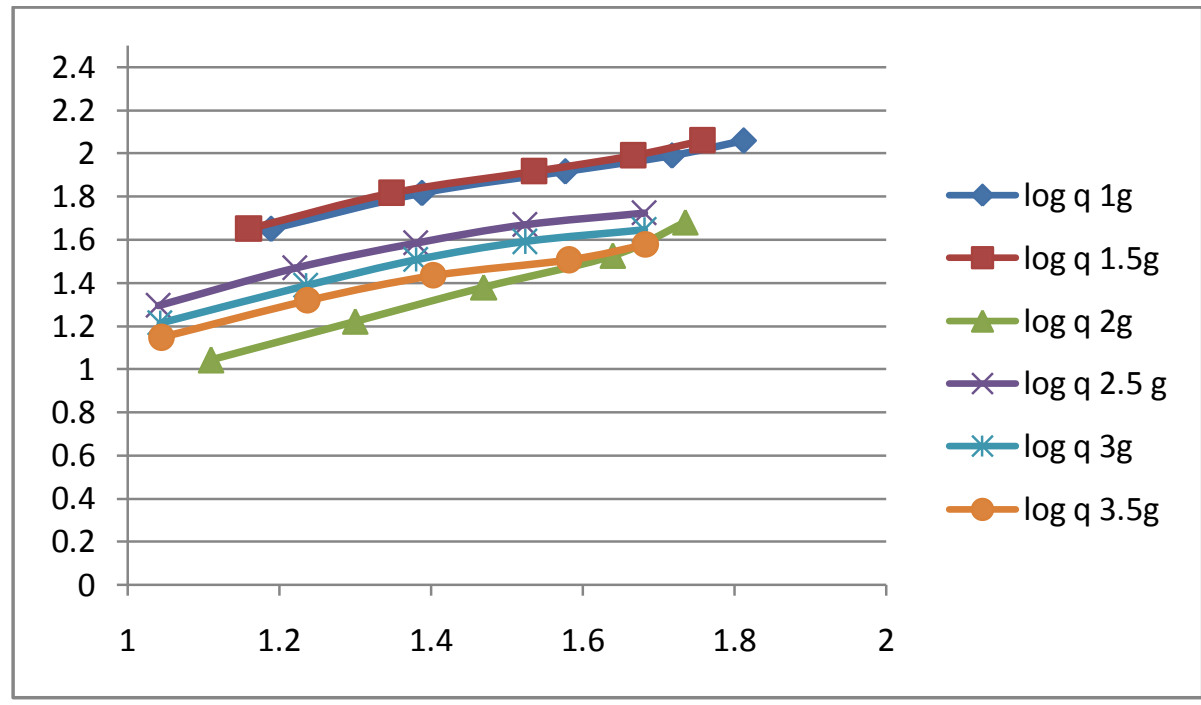

Fig. 5 (a) Biosorption isotherm $\log \mathrm{Ce}(\mathrm{mg} / \mathrm{L})$ vs $\log \mathrm{qe}(\mathrm{mg} / \mathrm{g})(\mathrm{ACSP})$

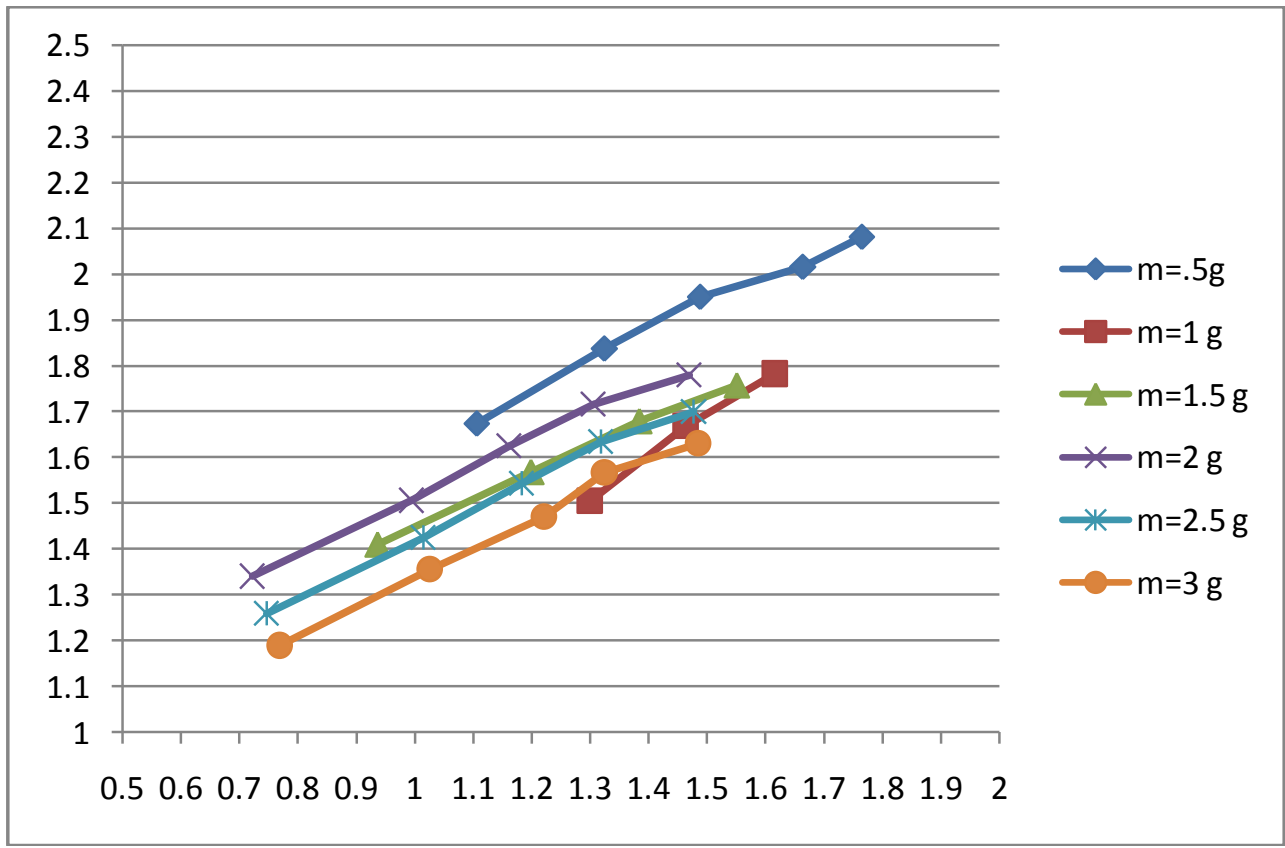

Fig. 5 (b) Biosorption isotherm $\log \mathrm{Ce}(\mathrm{mg} / \mathrm{L})$ vs $\log$ qe (mg/g) (PVAC-SP) 


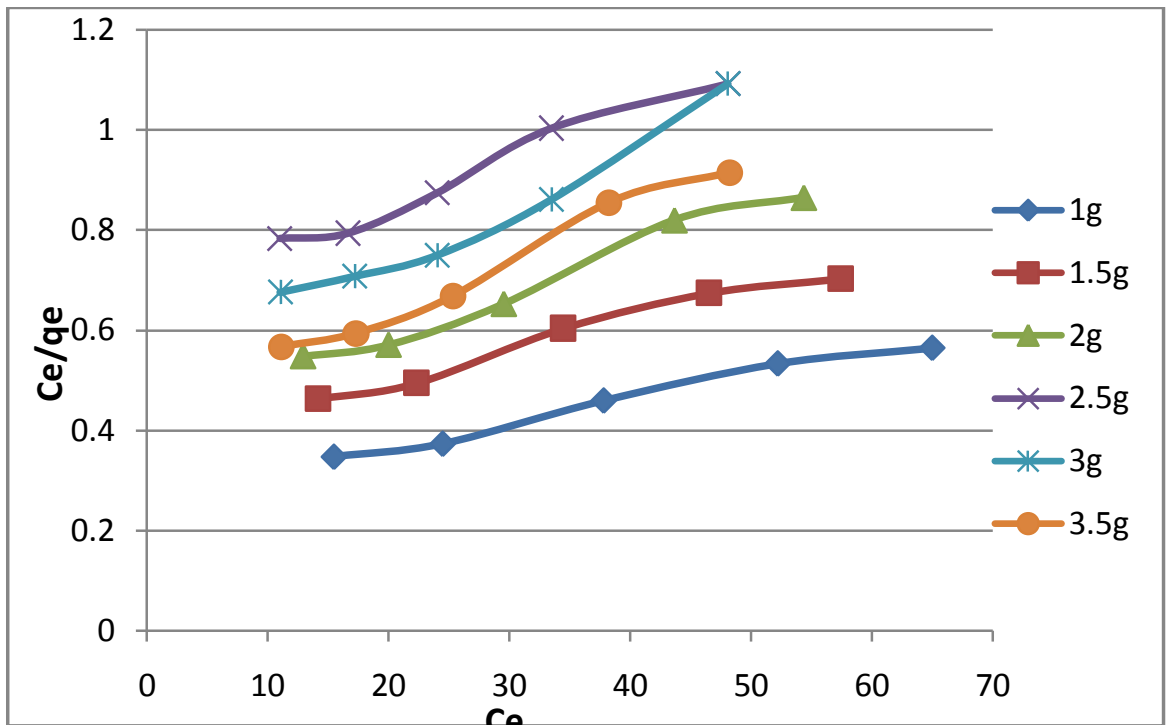

Fig 6(a) Langmuir isotherm for Cd(II) ions removal on ACSP

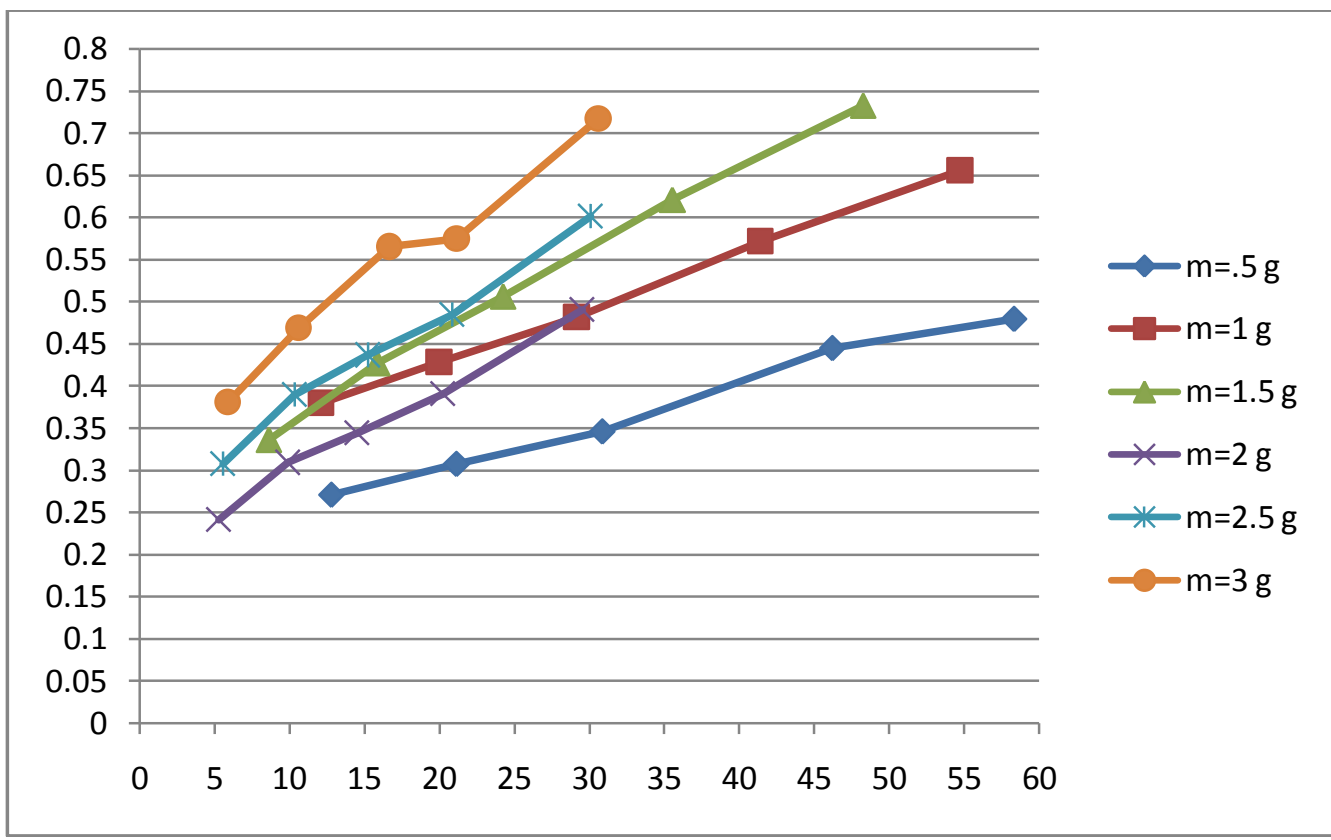

Fig 6 (b) Langmuir isotherm $\mathrm{Ce} / \mathrm{q}_{\mathrm{e}}$ vs Ce for $\mathrm{Cd}(\mathrm{II})$ ions removal on PVAC-SPs

Tables:

1.a : Table for Langmuir isotherm (ACSP)

\begin{tabular}{|c|c|c|c|c|c|c|c|}
\hline $\mathrm{m}$ & $\mathrm{Qo}=1 / \mathrm{m}$ & $\mathrm{C}=$ intercept & $\mathrm{Qo}^{*} \mathrm{C}$ & $\mathrm{b}$ & b.Co & $1+\mathrm{bCo}$ & $\mathrm{Rl}=1 / 1+\mathrm{b} . \mathrm{Co}$ \\
\hline 0.004 & 250 & 0.272 & 68 & 0.0147 & 0.882 & 1.882 & 0.53134 \\
\hline 0.006 & 166.66 & 0.379 & 63.164 & 0.01583 & 0.9498 & 1.9498 & 0.51287 \\
\hline 0.008 & 125 & 0.421 & 52.625 & 0.019 & 1.14 & 2.14 & 0.46728 \\
\hline 0.009 & 111.11 & 0.668 & 74.22 & 0.013473 & 0.80838 & 1.80838 & 0.553 \\
\hline 0.011 & 90.9 & 0.513 & 46.631 & 0.02144 & 1.2864 & 2.2864 & 0.4373 \\
\hline 0.01 & 100 & 0.434 & 43.4 & 0.02304 & 1.3824 & 2.3824 & 0.4197 \\
\hline
\end{tabular}


1 (b). Table for Freundlich isotherm(ACSP)

\begin{tabular}{|r|r|r|r|r|r|}
\hline $\mathrm{m}=1 / \mathrm{n}$ & \multicolumn{1}{|c|}{$\mathrm{n}$} & $\mathrm{C}=\log \mathrm{Kf}$ & \multicolumn{1}{c|}{$\mathrm{Kf}$} & \multicolumn{1}{c|}{$\mathrm{r}$} & \multicolumn{1}{c|}{$\mathrm{r} 2$} \\
\hline 0.635 & 1.574 & 0.908 & 8.09 & 0.994 & 0.99 \\
\hline 0.686 & 1.457 & 0.704 & 5.05 & 0.995 & 0.991 \\
\hline 0.654 & 1.529 & 0.669 & 4.67 & 0.99 & 0.981 \\
\hline 0.673 & 1.485 & 0.478 & 3.01 & 0.982 & 0.966 \\
\hline 0.684 & 1.461 & 0.527 & 3.36 & 0.984 & 0.969 \\
\hline 0.649 & 1.54 & 0.637 & 4.33 & 0.9899 & 0.98 \\
\hline
\end{tabular}

Tables:

2 (a). Table for Langmuir isotherm (PVAC-SP)

\begin{tabular}{|c|c|c|c|c|c|c|c|}
\hline $\mathrm{m}$ & $\mathrm{Qo}=1 / \mathrm{m}$ & $\mathrm{C}=$ intercept & Qo*C & $\mathrm{b}$ & b.Co & $1+\mathrm{bCo}$ & $\mathrm{Rl}=1 / 1+\mathrm{b} . \mathrm{Co}$ \\
\hline .004 & 250 & 0.206 & 51.5 & 0.0194 & 1.164 & 2.164 & .462 \\
\hline 0.006 & 166.67 & 0.297 & 49.5 & 0.02 & 1.2 & 2.2 & .4545 \\
\hline 0.009 & 111.11 & 0.262 & 29.11 & 0.0343 & 2.05 & 3.05 & .3278 \\
\hline 0.009 & 111.11 & 0.198 & 21.999 & 0.0454 & 2.724 & 3.724 & .2685 \\
\hline 0.011 & 90.9 & 0.255 & 23.179 & 0.0431 & 2.586 & 3.586 & .2788 \\
\hline 0.013 & 76.92 & 0.319 & 24.537 & 0.0407 & 2.442 & 3.442 & .2905 \\
\hline
\end{tabular}

2 (b) Table for Freundlich isotherm ((PVAC-SP)

\begin{tabular}{|r|r|r|r|r|r|}
\hline $\mathrm{m}=1 / \mathrm{n}$ & \multicolumn{1}{|c|}{$\mathrm{n}$} & $\mathrm{C}=\log \mathrm{Kf}$ & \multicolumn{1}{c|}{$\mathrm{Kf}$} & \multicolumn{1}{c|}{$\mathrm{r}$} & \multicolumn{1}{c|}{$\mathrm{r} 2$} \\
\hline 0.603 & 1.658 & 1.024 & 10.5681 & .9924 & 0.985 \\
\hline 0.637 & 1.569 & 0.829 & 6.74528 & 0.9954 & 0.991 \\
\hline 0.55 & 1.818 & 0.903 & 7.9983 & 0.9974 & 0.995 \\
\hline 0.604 & 1.655 & 0.908 & 8.09095 & 0.9964 & 0.993 \\
\hline 0.619 & 1.615 & 0.8 & 6.3095 & 0.9969 & 0.994 \\
\hline 0.630 & 1.587 & 0.707 & 5.0933 & 0.9964 & 0.993 \\
\hline
\end{tabular}

